\title{
A Bibliografia Nacional Brasileira: histórico, reflexões e inflexões
}

\author{
The Brazil's National Bibliography: history, reflections and inflections \\ Carlos Henrique Juvêncio \\ Doutorando do Programa de Pós-Graduação em Ciência da Informação da Universidade de Brasília - UnB. \\ E-mail: carloshjuvsilva@ yahoo.com.br \\ Georgete Medleg Rodrigues \\ Doutora em História pela Université de Paris. \\ Professora do Programa de Pós-Graduação em Ciência da Informação da Universidade de Brasília - UnB. \\ E-mail: georgete@unb.br
}

\section{Resumo}

A Bibliografia Nacional tem papel de destaque como instrumento de pesquisa e memória da produção intelectual da sociedade. No âmbito de sua construção, este trabalho busca refazer a trajetória histórica de tal instrumento de controle bibliográfico no Brasil a partir do século XIX até os dias atuais tomando como norte a sua importância enquanto inventário da memória intelectual nacional. Utiliza como fonte de pesquisa documentos e publicações sobre o tema de diferentes épocas e em diferentes contextos, sobretudo, publicações destacadas por Edson Nery da Fonseca em suas mais diversas pesquisa sobre o tema. Problematiza a institucionalização da Bibliografia, enquanto disciplina, no país e sua contribuição para a construção da(s) bibliografia(s) nacional(is). Também visa elucidar os papéis exercidos por diferentes instituições ao longo da história como responsáveis pela construção de tal instrumento. Conclui que a Bibliografia Brasileira jamais foi construída plenamente e sempre foi perene frente à necessidade de constante atualização, além de não se tratar de uma política sólida de construção da memória nacional.

Palavras-chave: Bibliografia Nacional. Biblioteca Nacional. Controle Bibliográfico. História. Memória.

\begin{abstract}
The National Bibliography has an important role as a research tool and memory of the intellectual production of society. This work seeks to retrace the historical trajectory of such bibliographic control instrument in Brazil from the nineteenth century to the present day taking as north to its importance as a national inventory of intellectual memory. Uses as a source of research papers and publications on the subject of different times and in different contexts, especially publications highlighted by Edson Nery da Fonseca in its various research on the subject. Discusses the institutionalization of Bibliography as a discipline in the country and their contribution to the construction of the national bibliography. It also aims to elucidate the roles played by different institutions throughout history as responsible for the construction of the instrument. It concludes that the Brazilian Bibliography was never fully built and has always been perennial front of the need for constant updating, and not it is a sound policy of construction of national memory.
\end{abstract}

Keywords: Bibliographic Control. History. Memory. National Bibliography. National Library. 


\section{Considerações Iniciais}

De tradição milenar, as bibliografias são uma importante fonte de informação quanto à produção intelectual de determinada área do conhecimento, país, região ou autor. Sua origem remonta, segundo Reyes Gómez (2010), à Calímaco, bibliotecário de Alexandria, que ao criar as "Pinakes", ou a lista de obras que a instituição continha, dá início à tradição bibliográfica.

Seus tipos são variados, podendo ser sinaléticas - quando é realizada somente a descrição da obra -, ou analíticas - quando a obra é analisada sob múltiplos aspectos, incluindo os bibliológicos, mais voltados à materialidade do livro. Uma bibliografia pode ser, ainda, geral ou especializada em alguma área do conhecimento; ou de cunho nacional/regional (BALSAMO, [200-]; REYES GÓMEZ, 2010). Araújo (2015, p. 119) menciona que:

A Bibliografia é uma disciplina constituída por interfaces teóricas e práticas que, desde sua origem, tem fundamentado o tratamento documental, seja do ponto de vista de sua descrição, classificação, circulação e mediação. Paralelamente, a Bibliografia se ocupa do mapeamento e da representação dos saberes e do conhecimento.

Complementarmente, o autor ainda nos elucida que "A palavra bibliografia indica a disciplina (Bibliografia), seu objeto de estudo (ligado às teorias e aos métodos de produção de repertórios, aspectos da fisicalidade dos documentos, etc.) e o resultado dos processos documentários (as listas)" (ARAÚJO, 2015, p. 121). Ou seja, Bibliografia denota uma área do conhecimento/saber interessada nos métodos e técnicas de descrição de documentos visando a construção de fontes de informação que, dependendo de seu caráter e objetivo, serão generalistas e/ou especializadas.

Com efeito, se hoje o papel reservado à Bibliografia é secundário e até mesmo ignorado, deve-se à essa disciplina os processos e técnicas de descrição documental utilizados cotidianamente. Derivadas da evolução e aperfeiçoamento no decorrer dos séculos, as técnicas bibliográficas nos ajudaram, e ajudam, na organização do conhecimento produzido pela humanidade, seja pela padronização de descrições, utilização de classificações, pela elaboração de simples listas até a análise minuciosa obra à obra, de fato, corroboramos com Araújo (2015, p. 124), que:

[...] é inegável, do ponto de vista da história das disciplinas que lidam com a informação e com o documento, que a Bibliografia fundamentou as práticas e técnicas desenvolvidas posteriormente pela Documentação, Biblioteconomia e CI [Ciência da Informação], sobretudo na sua dimensão documental para concepção e desenvolvimento de listas e repertórios bibliográficos. 
No bojo do avanço de tal área no decorrer dos séculos, outro pioneiro na criação de bibliografias foi o médico grego Galeno, que no século II a.C. cria uma lista das obras da qual era autor visando eliminar dúvidas sobre a autenticidade de alguns de seus escritos, bem como negar a autoria de tantos outros. Já o pai das biobibliografias ${ }^{1}$ é São Jerônimo, que no século V arrola em sua obra De viris illustribus a biografia de vários autores eclesiásticos, bem como as obras por eles escritas (REYES GOMÉZ, 2010).

De fato, é durante o Medievo que as bibliografias se desenvolvem de forma acentuada, onde passam a "[...] contar com um princípio diretor constante em suas descrições: nome do autor, dignidade eclesiástica e lugar onde exerce, suas obras, valorização do conteúdo, atendendo à sua qualidade intelectual, e dados cronológicos" " (REYES GÓMEZ, 2010, p. 101). Outro fato destacado por Reyes Gómez (2010, p. 102) é de que:

Se até o século XII a cultura ocidental se conservava, fundamentalmente, nos monastérios, a partir do início do século XIII, com o nascimento das universidades, o acesso à leitura alcançou uma parte mais ampla da sociedade e a produção de livros aumentou de tal forma que gerou a necessidade de outro sistema mais rápido de organização ${ }^{3}$.

Logo, é à reboque do desenvolvimento científico e tecnológico experimentado a partir do século XIII que as bibliografias se desenvolvem; se dantes eram listas de obras de algumas personalidades e, sobretudo, de livros eclesiásticos, a partir de então as obras passam a ser de referência para as áreas de conhecimento em voga, servindo de referência para se saber o que se construía em termos científicos, bem como verificar o estado d'arte das ciências (BALSAMO, [200-]; REYES GÓMEZ, 2010).

Assim, se a abertura das universidades ajuda na difusão das bibliografias, é com o advento da imprensa, no século XV, que elas se difundem ainda mais na Europa e de forma muito mais rápida, visando ser um verdadeiro extrato dos documentos produzidos sobre os mais variados temas e assuntos, experimentando as facilidades que a prensa de tipos móveis oferece. É nesse período, por exemplo, que as bibliografias comerciais começam a ser lançadas; o objetivo, segundo os editores, era difundir os livros por eles impressos e facilitar as vendas,

\footnotetext{
${ }^{1}$ Modalidade de bibliografia onde, além de relacionar as obras escritas pelos personagens, traz sua biografia. Segundo Cunha e Cavalcanti (2008, p. 56) é o "estudo da vida e das obras de um autor [...]; em geral, inclui a referência a textos críticos sobre o autor e suas obras".

2 [...] cuenta com um principio diretor constante em sus descripciones: nombre del autor, dignidade eclesiástica y lugar donde ejerce, sus obras, valoración del contenido, atendiendo a su calidad intelectual, y datos cronológicos.

${ }^{3}$ Si hasta el siglo XII la cultura occidental se conservaba, fundamentalmente, em los monastérios, a partir dos comienzos del XIII, com el nacimiento de las universidades el acceso a la lectura se abrió a uma parte más amplia de la sociedade y la producción de libros aumento hasta llevar a la necesidad de outro sistema más rápido de elaboración.
}

InCID: R. Ci. Inf. e Doc., Ribeirão Preto, v. 7, n. esp., p. 165-182, ago. 2016. 
servindo como meio de propaganda e, ao mesmo tempo, de controle do que era produzido (BALSAMO, [200-]). Nesse bojo:

\begin{abstract}
A primeira bibliografia sistemática publicada, Liber de scriptoribus ecclesiasticis (1494), é de autoria de Johannes Trithemius ${ }^{4}$ (1462-1516). Foi o primeiro repertório biobibliográfico da Idade Moderna que, embora tenha esse título, não se limita às obras de escritores eclesiásticos no sentido estrito mas, no âmbito da civilização cristã, incorpora escritos filosóficos, científicos e literários (ARAÚJO, 2015, p. 127).
\end{abstract}

Sendo assim, Trithemius é considerado o pai da bibliografia moderna que, para além de uma lista de livros, representa uma fonte de informação que segue padrões bem estabelecidos e é um produto da prática bibliográfica.

Cabe-nos aqui fazer uma ressalva à função das bibliografias pois, apesar de enaltecermos seu lado de difusora da informação, ela também possui um lado atrelado à privação do acesso à informação, ou seja, censura. Seu maior expoente é o Index Librorum Prohibitorum $^{5}$, editada do século XVI ao XX, esta bibliografia reunia as obras proibidas pela Igreja Católica. Os motivos para entrar na lista eram diversos, iam desde serem textos que contestavam o Papa, até tratados astronômicos. Sendo proibidos, os livros eram retirados do mercado ou censurados manualmente com a rasura de partes consideradas indevidas (CALLEGARI, 2012).

Porém, se Trithemius é o pai da bibliografia moderna, seu maior expoente é Conrad Gesner que, em 1545, lança do primeiro volume de sua Bibliotheca Universalis. Tal obra é a primeira voltada à organização universal do conhecimento bibliográfico humano, visando arrolar todos os autores da época, bem como suas obras. Editada em 4 partes ${ }^{6}$, nela:

Gesner organiza cada obra a partir das categorias previamente definidas e coloca em prática seu pensamento esquemático: na medida em que foi naturalista, ao trabalhar com a classificação dos seres, foi também bibliógrafo, ao trabalhar com a classificação dos saberes. Estava interessado em classificar tanto livros quantos os animais. Assim, promoveu uma espécie de "anatomização" da biblioteca e do conhecimento, sugerindo que o próprio ato de anatomizar dava bases para o ato de classificar (ARAÚJO, 2015, p. 134).

Assim, Gesner, mais do que fazer um inventário de toda a produção bibliográfica de seu tempo, acaba por categorizar o conhecimento, facilitando a recuperação das obras. Por certo, Araújo (2015) observa outra motivação na construção da Bibliotheca, pois, além de ser uma fonte de informação/inventário, ela busca preservar a memória contida nos registros

\footnotetext{
${ }^{4}$ A grafia do nome do personagem varia podendo se apresentar como Johann Tritheim.

${ }^{5}$ O Îndice de Livros Proibidos, em tradução livre, teve sua primeira edição em 1558 e a última de 1966.

6 “A obra foi publicada em quatro partes, entre 1545-1555: 1) Bibliotheca Universalis, sive Catalogus omnium scriptorum locupletissimus, in tribus linguis, Latina, Graeca, et Hebraica [...]; 2) Pandectarum sive partitionum universalium [...] (1548); 3) Partitiones theologicae (1549) e 4) Appendix bibliothecae (1555) (p. 129-130)" (ARAÚJO, 2015, p. 129-130).
}

InCID: R. Ci. Inf. e Doc., Ribeirão Preto, v. 7, n. esp., p. 165-182, ago. 2016. 
documentais, pois, se não podemos salvar a materialidade do registro, podemos ao menos ter noção de sua existência no curso da história da humanidade ${ }^{7}$. Tal fato é ilustrado pela constatação de Gesner de que durante a invasão turca à $\mathrm{Buda}^{8}$, em 1527, a biblioteca de Matías Corvino, rei da Hungria, além dos danos causados pelo saque e incêndio, sofreu prejuízo irreversível, uma vez que se perdeu todo o conhecimento sobre o que havia na instituição, além das próprias obras, incluindo títulos únicos (ARAÚJO, 2015).

Com efeito, até hoje a obra de Gesner continua a ser singular, pois, como nos elucida Araújo (2015), foi e é a única a realizar por completo o intento universal de representação do conhecimento humano. Desta forma, abaixo seguem alguns marcos da Bibliografia com a finalidade de melhor explicitar a sua história e evolução:

Quadro 1 - Marcos Históricos da Bibliografia

\begin{tabular}{|c|c|c|c|}
\hline ANO & PERSONAGEM & OBRA/HISTÓRICO & DESCRIÇÃO \\
\hline Séc. III a.C. & Calímaco & Pinakes & $\begin{array}{c}\text { Lista de livros da Biblioteca de } \\
\text { Alexandria }\end{array}$ \\
\hline Séc. II a.C. & Galeno & $\begin{array}{l}\text { De ordine librorium suorum } \\
\text { liber }\end{array}$ & $\begin{array}{l}\text { Lista de obras do médico grego, } \\
\text { Galeno. }\end{array}$ \\
\hline Séc. V & São Jerônimo & De viris illustribus & $\begin{array}{l}\text { Bibliografia de } 135 \text { autores } \\
\text { eclesiásticos. }\end{array}$ \\
\hline 1410 & $\begin{array}{l}\text { John Boston de } \\
\text { Bury }\end{array}$ & Catalogus Scriptorum Ecclesias & $\begin{array}{c}\text { Bibliografia de } 195 \text { obras existentes } \\
\text { em monastérios ingleses. }\end{array}$ \\
\hline 1494 & $\begin{array}{l}\text { Johannes } \\
\text { Trithemius } \\
\end{array}$ & $\begin{array}{c}\text { Liber de scriptoribus } \\
\text { ecclesiasticis }\end{array}$ & $\begin{array}{l}\text { Bibliografia de mais de mil autores } \\
\text { europeus e sete mil obras. }\end{array}$ \\
\hline 1506 & $\begin{array}{l}\text { Symphorien } \\
\text { Champier }\end{array}$ & De medicinae claris scriptoribus & Primeira bibliografia especializada. \\
\hline 1545 & Conrad Gesner & Bibliotheca Universalis & Primeira Bibliografia Universal. \\
\hline 1549 & John Bale & $\begin{array}{l}\text { Scriptorum ilustrium majoris } \\
\text { Britanniae Catalogus }\end{array}$ & $\begin{array}{l}\text { Bibliografia que reúne obras de } \\
\text { autores ingleses. É considerada a } \\
\text { primeira bibliografia nacional. }\end{array}$ \\
\hline 1633 & Gabriel Naudé & Bibliographia Politica & $\begin{array}{c}\text { Bibliografia especializada em } \\
\text { política. }\end{array}$ \\
\hline 1664 & Philippe Labbé's & Bibliotheca Bibliothecarum & $\begin{array}{c}\text { Primeira bibliografia de } \\
\text { bibliografia. }\end{array}$ \\
\hline 1727 & Jean-Pierre Nicerón & $\begin{array}{c}\text { Mémoires pour servir à l'histoire } \\
\text { des hommes illustres, de la } \\
\text { république des lettres, avec un } \\
\text { catalogue raisonné de leurs } \\
\text { ouvrages }\end{array}$ & $\begin{array}{l}\text { Bibliografia voltada para bibliófilos } \\
\text { e estudiosos do livro. }\end{array}$ \\
\hline
\end{tabular}

Fonte: Elaboração do autor com base em Reyes Gómez (2010).

Contudo, é curioso notar que ápice das bibliografias acontece no século XIX, quando, segundo Reyes Gómez (2010), ela alcança sua maturidade, proporcionando uma série de reflexões teórico-metodológicas. Tal século ainda agrega à ideia tão em voga de nacionalismo

\footnotetext{
${ }^{7}$ Não pretendemos esboçar tal tema profundamente, mas pensamos o quão seria interessante inventariar cada obra contida no Bibliotheca Universalis a fim de verificar quais obras ainda existem hoje e quais são somente um registro de uma época passada.

${ }^{8}$ Buda se torna, após a fusão com Peste, Budapeste, atual capital da Hungria.
}

InCID: R. Ci. Inf. e Doc., Ribeirão Preto, v. 7, n. esp., p. 165-182, ago. 2016. 
e faz explodir o número de bibliografias nacionais, buscando tecer um inventário da produção bibliográfica de cada país ou território. Assim, é sob este prisma que desenvolveremos este trabalho, buscando refazer a trajetória histórica de tal instrumento de controle bibliográfico no Brasil a partir do século XIX até os dias atuais tomando como norte a sua importância enquanto inventário da memória intelectual nacional.

\section{O Passado Bibliográfico Brasileiro}

O Brasil, em relação aos seus vizinhos Sul-americanos, experimenta um tipo de colonização marcada, sobretudo, pela espoliação de suas riquezas e o desinteresse pelo desenvolvimento científico e/ou intelectual na então Colônia. De fato, a política lusófona para seus domínios ultramar diferia da espanhola, britânica ou holandesa. Schwartzman (2001) observa que diferentemente de seus vizinhos europeus, Portugal sofria forte influência da Igreja não só na vida social de sua população, mas também em seu governo. Nenhuma decisão era tomada sem que se consultasse os Jesuítas ${ }^{9}$, além de serem eles os responsáveis pelo controle da educação no país, logo, eram quem ditava o que deveria ser lido, ensinado ou, até mesmo, publicado em Portugal e em seus territórios.

Tal influência perdurou por cerca de três séculos e resultou, segundo Schwartzman (2001), num atraso considerável de Portugal em relação às demais potências europeias, uma vez que, se antes os portugueses detinham o domínio das técnicas de navegação e engenharia marítima graças, sobretudo, à influência árabe na Península Ibérica, com os jesuítas o que se viu foi a estagnação, ou, até mesmo, o retrocesso dos ofícios navais e não desenvolvimento de uma "ciência portuguesa", justo no momento em que a Europa vivia seu período de Renascimento, entre os séculos XV e XVIII. "Inicialmente, Portugal desempenhou um papel pioneiro nas transformações que começaram a sacudir a Europa a partir do Renascimento. Mais tarde, porém, teria um papel marginal, com efeitos profundos sobre a herança cultural que o Brasil iria receber" (SCHWARTZMAN, 2001, p. 40).

\footnotetext{
9 “Jesuíta é um membro da Companhia de Jesus, ordem religiosa ligada à Igreja Católica Romana fundada por Santo Inácio de Loyola, tendo reconhecimento pelo seu método educacional, missionário, e obras de caridade. Considerada por muitos como o principal agente da Contra-Reforma, e mais tarde uma força de liderança na modernização da igreja, os jesuítas sempre foram um grupo controverso, considerado por alguns como uma sociedade a ser temida e condenada e por outros como a mais louvável e estimada ordem religiosa na Igreja Católica Romana” (ENCICLOPAEDIA BRITANNICA, c2015, tradução nossa).
} 
Carlos Henrique Juvêncio e Georgete Medleg Rodrigues

Assim, se o século XV começa com a organização da Escola de Sagres pelo Infante Dom Henrique, visando o aperfeiçoamento dos navios e instrumentos náuticos, e termina com a descoberta do Brasil, em 1500, a partir de então, o ideário jesuítico passa a estar em voga e a desconstruir os feitos portugueses utilizando como motivo a religião.

[...] Os jesuítas não se opunham a novas informações ou técnicas, mas não toleravam o ponto de vista filosófico mais amplo e as instituições intelectuais inovadoras que haviam surgido em algumas partes da Europa. As questões que os professores deviam levantar e os textos que os estudantes deviam ler estavam sujeitos a um controle estrito. A obediência às autoridades religiosas devia ser respeitada em todas as questões relacionadas com a disciplina e o estudo; nas explicações, nenhuma referência era feita a autores ou livros não autorizados; nenhum novo método de ensino ou de discussão devia ser introduzido, e a ninguém se permitia levantar novas questões ou apresentar opinião que não fosse de um autor qualificado, exceto quando devidamente autorizado a fazê-lo.

[...]

Essa doutrina pedagógica não era usada apenas para preservar a integridade e a pureza de uma única ordem religiosa, mas tornou-se uma norma aplicável a toda a nação portuguesa. Os jesuítas assumiram o controle da educação em todos os níveis [...]. Além disso, essa doutrina permeava a administração do Estado português. O resultado foi uma barreira impenetrável estendida em torno de Portugal, isolando-o inteiramente da cultura moderna (SCHWARTZMAN, 2001, p. 44-45).

Este cenário só teve fim em 1759, quando o Marques de Pombal expulsa os jesuítas da Corte Portuguesa e de seus domínios ultramar e inicia uma grande reforma nas instituições de ensino portuguesas, sobretudo em Coimbra. Contudo, para o Brasil, o panorama só se modifica em 1808, quando a Família Real desembarca no hemisfério sul, buscando se refugiar do ímpeto napoleônico (SCHWARTZMAN, 2001).

Fundada em 1808,a Imprensa Régia parece ser o primeiro indicativo de que a situação bibliográfica brasileira poderia ter um cenário menos nebuloso no alvorecer do século XIX, se antes, com a censura, a existência de casas editoriais ou de maquinário de impressão representava a prisão de seu(s) dono(s) e a destruição desta, com a chegada da Corte o panorama se torna favorável e o Príncipe Regente, D. João VI, permite que sejam realizadas as primeiras impressões em solo brasileiro com autorização de Portugal ${ }^{10}$.

Contudo, apesar de imaginarmos a grande explosão bibliográfica com o advento da prensa no Brasil, a primeira obra que intenta ser um inventário da produção intelectual nacional só surge em 1881, ou seja, 73 anos após a instalação da Imprensa Régia, quando Ramiz Galvão, então diretor da Biblioteca Nacional, edita o Catálogo de Exposição da História do Brasil. Donde parte-se da premissa de que toda, ou grande parte, da memória bibliográfica brasileira

\footnotetext{
${ }^{10}$ Permita-nos tecer aqui duas observações. A primeira diz respeito ao fato de que durante a ocupação holandesa do nordeste brasileiro, no século XVII, imprimiu-se livros no Brasil. Segundo, suspeita-se, também, da existência de oficinas tipográficas clandestinas no país, mas, até hoje, nada foi provado.
} 
estaria ali arrolada, uma vez que a Biblioteca era a responsável pela guarda dos registros relativos à história da nação.

Ainda no bojo das ações da Biblioteca Nacional, é editado entre 1886 a 1888 o Boletim das Aquisições mais Importantes feitas pela Bibliotheca Nacional, organizado por João de Saldanha da Gama e classificado segundo as quatro Seções em que estava organizada a Biblioteca Nacional: Imprensa, Manuscritos, Estampas e Numismática (FONSECA, 1972).

Após este período, em 1888, no bojo da antagonismo entre Republicanos e Monarquistas, surge, pelas mãos do Centro Bibliographico Vulgarisador, a Bibliographia Brazileira.

O Centro Bibliographico Vulgarisador Compra e vende livros raros e preciosos; restos de edições e edições inteiras; bibliothecas particulares e livrarias para liquidar.

Permuta obras estrangeiras e nacionaes, e serve de intermediario para com as livrarias da provincia e do estrangeiro.

Encarrega-se de liquidar por meio de vendas, leilões geraes e parciaes, livrarias, bibliothecas e edições. Organisando para isso catalogos e encarregandp-se da sua publicação e vulgarisação. Encarrega-se de mandar vir de qualquer mercado livros, mappas e estampas, raras, preciosas ou vulgares e de remetter para o interior.

Encarrega-se de publicações por conta dos autores, do governo geral ou provincial; da distribuição pela imprensa nacional e estrangeira bem como da respectiva venda e propaganda. A commissão depende da importancia do encargo e dos meios necessarios á sua realisação variando de $20 \%$ a $40 \%$.

A todas as Bibliothecas

do imperio, quer mantidas pelos cofres publicos, quer por associações particulares, remetteremos gratuitamente esta Revista, desde que seja reclamada por escripto. Pedimos em troca unicamente uma noticia da Bibliotheca e da instituição a que pertencer, bem como uma nota estatistica do movimento mensal, trimensal, semestral ou anual (BIBLIOGRAPHIA Brazileira, 1888, p. 7).

Tal sociedade visa:

[...] a compra e venda, publicação e vulgarisação de livros, principalmente de autores brazileiros e a fundação de uma bibliotheca technica para servir de base ao estudos da imprensa no Brazil. Para isto a sociedade fará a publicação mensal de um boletim com o titulo de Bibliographia Brazileira (BIBLIOGRAPHIA Brazileira, 1888, p. 10).

De fato, tal bibliografia ganha repercussão internacional, sendo arrolada no Bulletin de L'Institut International de Bibliographie em 1908, sendo nomeada como a bibliografia corrente brasileira e editada mensalmente na Revista Sul Americana ${ }^{11}$. Cumpre-nos esclarecer que a Bibliographia surge como edição independente em 1888, mas é incorporada à Revista Sul Americana em 1889, ano de sua extinção, o que não impede de, quase 20 anos depois, o Instituto Internacional de Bibliografia (IIB) a reconheça como a Bibliografia Nacional do Brasil.

\footnotetext{
${ }^{11}$ Bibliographie: Revista Sul Americana (contenant la Bibliographie courant du Brésil) (BULLETIN de L'Institut
} International de Bibliographie, 1908). 
Carlos Henrique Juvêncio e Georgete Medleg Rodrigues

Ademais, só após dez anos da menção no Bulletin que uma nova Bibliografia Nacional seria editada em nosso país com a criação do Boletim bibliographico da Bibliotheca Nacional do Rio de Janeiro. Organizada por Cícero de Britto Galvão, a bibliografia foi editada entre os anos de 1918 e 1921, contando com 14 volumes produzidos conforme as normas do IIB, concebidas por Paul Otlet e Henri La Fontaine, com as informações preenchendo apenas o anverso da folha, com espaço suficiente para que fossem recortadas e coladas em fichas padrão 7,5 cm X 12,5 cm. Assim, “O Boletim Bibliographico, finalmente vem á luz publica sem originalidade de maior, porquanto para elle se adoptou o melhor modelo conhecido que é o do Institut Internationale de Bruxelles ${ }^{12}$ " (MAGALHÃES, 1918).

A citação a seguir, embora longa, é necessária para que possamos compreender efetivamente o alcance dessa iniciativa. Magalhães (1919-1920, p. 292-293), diretor interino da BN e autor do relatório institucional referente ao ano de 1918, escreveu que:

Devo fazer menção especial do "Boletim Bibliographico", porque, embora para a sua organização definitiva houvesse eu apenas contibuido com ligeiros retoques, veiu elle a lume sob a minha administração interina, e o reputo de um dos mais consideraveis melhoramentos ultimamente introduzidos nesta Bibliotheca.

Era uma obrigação estatuida pelo Decreto n. 1.825 de 20 de dezembro de 1907, e pelo Regulamento da Bibliotheca Nacional, de 11 de Junho de 1911. Não tinha sido, porém, cumprida, o que dava aso a reclamações procedentes e curiosas, qual a de certo editor estabelecido na Bahia, o qual, toda vez remettia á Bibliotheca nacional cada exemplar das obras que estampava, dizia e interrogava: - "Eu estou cumprindo o dever a que força a lei. Quando é, entretanto, que a Bibliotheca se dispõe a cumprir o seu?". Não reiterarei aqui as longas explicações que, firmadas por mim e pelo director da $1 .{ }^{a}$ secção, servem de prefacio ao numero do "Boletim Bibliographico". Limitar-me-ei a corroborar a justa asserção do dr. Constancio Alves - de que o "Boletim Bibliographico", desde que a Bibliotheca effectivamente receba, por virtude do decreto n. 1. 1825, um exemplar de cada obra editada em nosso paiz, será o "registro completo da actividade intellectual do Brasil", além de "proporcionar a quantos estudam um instrumento de trabalho como nunca possuimos e cuja utilidade é desnecessaria apontar".

Ficou encarregado da organização do "Boletim Bibliographico"; para qual se adoptou o melhor modelo conhecido, que é o do Institut de Bibliographie International de Bruxelles, o official Cicero de Brito Galvão, não ha muito chegado de uma viagem de estudos e pesquizas na Europa, especialmente na Belgica.

Tendo-se resolvido que a publicação fosse trimestal, os numeros I e II sairam dos prelos com regularidade; mas, em consequencia da epidemia que alteou esta Capital no mezes de outubro e novembro e ainda por motivos da deficiencia da pressão por parte do gaz de que se servem os nossos linotypos, ficaram bastante atrazados os numeros III e IV, os quaes, formando um tomo unico, serão distribuidos em começo do corrente anno.

12 Optou-se, neste trabalho, por não fazer a atualização dos vocábulos das citações para as normas gramaticais e gráficas atuais. Entendemos que desta forma, mantemos a fidedignidade dos textos.

InCID: R. Ci. Inf. e Doc., Ribeirão Preto, v. 7, n. esp., p. 165-182, ago. 2016. 
Nesse sentido, com a edição do Boletim Bibliographico da Bibliotheca Nacional do Rio de Janeiro os esforços de cooperação e intercâmbio entre a Biblioteca Nacional brasileira e o Instituto Internacional de Bibliografia ficam mais evidentes.

Fonseca (1972) observa que a Bibliografia Brasileira é, sobretudo, marcada por interrupções e descontinuidade, assim, não seria diferente com o Boletim Bibliographico da BN que, após a morte de Cícero de Britto Galvão em 1920, sofre um hiato de mais de uma década, retornando somente no final dos anos de 1930 (Figura 1).

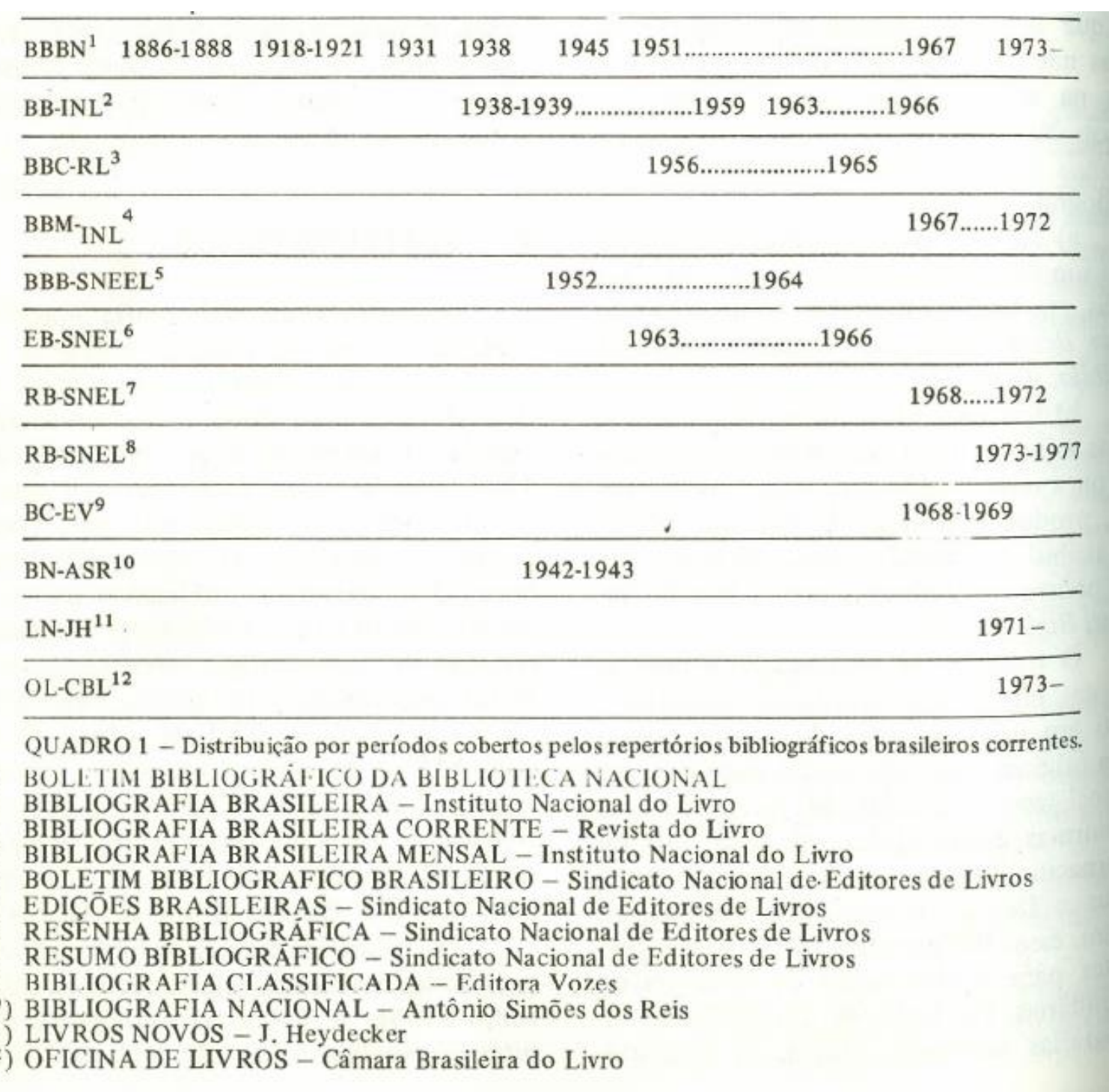

Figura 1: Mapa da evolução da Bibliografia Nacional.

Fonte: Caldeira; Carvalho (1980).

Entre as décadas de 1940 e 1980, duas instituições, segundo Fonseca (1972), revezamse na edição da Bibliografia Brasileira: Biblioteca Nacional e Instituto Nacional do Livro, conforme podemos verificar no quadro acima. Contudo, é em meados da década 1990, mais precisamente em 1997, que a Biblioteca Nacional, àquela altura, a única responsável pela edição 
da Bibliografia, uma vez que o Instituto do Livro havia sido extinto em idos de 1990, resolve por editar a Bibliografia apenas no formato digital e é isso que exploraremos melhor na próxima seção.

\section{A Biblioteca do Nacional?}

Desde o século XIX, com pequenos períodos de exceção, a Biblioteca Nacional está imbuída de elaborar e disseminar a Bibliografia Brasileira apoiada, sobretudo, no Depósito Legal instituído por lei. Contundo, se num primeiro momento o maior obstáculo era que a lei de 1847 (BRASIL, 1847) exigia que apenas os editores da Corte enviassem exemplares à Biblioteca - nas demais províncias o envio deveria ser feito às Bibliotecas Públicas de cada uma delas -; com a lei de 1907 (BRASIL, 1907) a obrigação passou a ser de todos os editores nacionais, contudo, várias desculpas eram utilizadas para o não cumprimento da Lei, tais como a distância das províncias da, àquela altura, Capital Federal, ou o custo de tal dever, por exemplo. Decerto, durante a gestão de Peregrino da Silva na BN, ao menos uma comissão foi encarregada de ir a cada província do país e inquirir os editores sobre o porquê do não cumprimento da legislação (SILVA, 1908).

De fato, a situação ainda se mantém hoje, e a Biblioteca é a responsável por receber os exemplares advindos da Lei de Depósito Legal e, como consequência, editar a Bibliografia Nacional Brasileira, diz ela que:

$\mathrm{O}$ acervo da $\mathrm{BN}$ cresce constantemente a partir da lei do depósito legal - que assegura o registro e a guarda da produção intelectual nacional, além de possibilitar o controle, a elaboração e a divulgação da Bibliografia Brasileira corrente, bem como a defesa e a preservação da língua e da cultura nacionais -, além de doações e aquisições.

A BN se caracteriza como uma biblioteca "nacional" por:

- ser beneficiária do instituto do Depósito Legal;

- elaborar e divulgar a bibliografia brasileira corrente, através dos Catálogos online;

- $\quad$ ser o centro nacional de permuta bibliográfica, com campo de ação internacional (BIBLIOTECA NACIONAL, [200-a]).

Com efeito, a legislação mais recente sobre o depósito legal é a lei 10.994, que diz:

Art. 1ํㅡㄹ Esta Lei regulamenta o depósito legal de publicações, na Biblioteca Nacional, objetivando assegurar o registro e a guarda da produção intelectual nacional, além de possibilitar o controle, a elaboração e a divulgação da bibliografia brasileira corrente, bem como a defesa e a preservação da língua e cultura nacionais (BRASIL, 2004).

Ser o órgão responsável por receber as publicações do depósito legal e responsável pela edição da Bibliografia Nacional é uma atribuição das Bibliotecas Nacionais desde as suas 
fundações. Advindas, em sua maioria, das Reais Bibliotecas; enquanto parte da Coroa, eram em suas prateleiras que se depositavam as obras editadas sob o Privilégio Real - uma espécie de Depósito Legal rudimentar e que tinha mais relação com o símbolo e poder real do que propriamente com a formação de uma memória dita nacional (CHARTIER, 2000).

Desta tradição, derivam-se várias das funções das Nacionais, logo, a Biblioteca Nacional brasileira tem por missão:

[...] coletar, registrar, salvaguardar e dar acesso à produção intelectual brasileira, assegurando o intercâmbio com instituições nacionais e internacionais e a preservação da memória bibliográfica e documental do país.

Compete à Biblioteca Nacional:

1. captar, preservar e difundir os registros da memória bibliográfica e documental nacional;

2. adotar as medidas necessárias para a conservação e proteção do patrimônio bibliográfico e digital sob sua custódia;

3. atuar como centro referencial de informações bibliográficas;

4. atuar como órgão responsável pelo controle bibliográfico nacional;

5. ser depositária e assegurar o cumprimento da legislação relativa ao depósito legal;

6. registrar obras intelectuais e averbar a cessão dos direitos patrimoniais do autor;

7. promover a cooperação e a difusão nacionais e internacionais relativas à sua missão;

8. fomentar a produção de conhecimento por meio de pesquisa, elaboração e circulação bibliográficas referentes à sua missão (BIBLIOTECA NACIONAL, [200-b]).

Como Fonseca (1972), Monte-Mór (1981) e Grings; Pacheco (2010) nos elucidam, a Bibliografia Brasileira sempre sofreu com hiatos, nunca foi uma política longeva ou que resistisse às trocas de comando na BN ou em outras instituições. Assim, desde 1997 a Biblioteca deixa de editar a Bibliografia em papel sob o pretexto de que esta estaria acessível no site da própria instituição, na forma de seu catálogo on-line ${ }^{13}$ - desconsiderando as diferenças entre o catálogo e uma bibliografia, afinal não é o objetivo deste artigo, gostaríamos de observar algumas questões:

1) Apesar de deixar claro em sua apresentação que é a responsável por "elaborar e divulgar a bibliografia brasileira corrente, através dos Catálogos online”, não há nenhum espaço em seu portal ${ }^{14}$ indicando sobre a consulta de tal fonte de informação;

2) Por meio de contato eletrônico com a Biblioteca, a instrução dada é que se pesquisasse no catálogo on-line pelo ano da bibliografia em questão. Naturalmente, essa nos parece ser a solução mais aceitável, apesar de considerarmos que não é a mais eficiente em termos de busca, já que deveriam existir outros filtros. Contudo, ao se pesquisar, como já esperávamos, o

\footnotetext{
${ }^{13}$ Acessível por meio do seguinte link: http://acervo.bn.br/sophia_web/index.html

${ }^{14}$ Acessível por meio do seguinte link: http://www.bn.br
} 
Carlos Henrique Juvêncio e Georgete Medleg Rodrigues

catálogo limitou-se a mostrar os 500 primeiros resultados da busca por conta de configurações técnicas (Imagem 2).

\begin{tabular}{|l|l|l|l|l|l|}
\hline FUNDAÇÃO BIBLIOTECA NACIONAL \\
\hline Busca rápida
\end{tabular}

Figura 2: tela de pesquisa do catálogo on-line da Biblioteca Nacional (busca por ano).

Fonte: Catálogo on-line da Biblioteca Nacional.

3) Relatado o problema, nos foi indicado que se realizasse a busca no catálogo geral com o código "BNB 01/2014 até 06/2016", dividindo por bimestres. O que resultou no mesmo alerta do sistema e o pior, indica a impossibilidade de geração de uma lista única por ano por parte do software utilizado pela Biblioteca.

SophiA Biblioteca-Tern $\times$

\section{FUNDAÇÃO BIBLIOTECA NACIONAL}

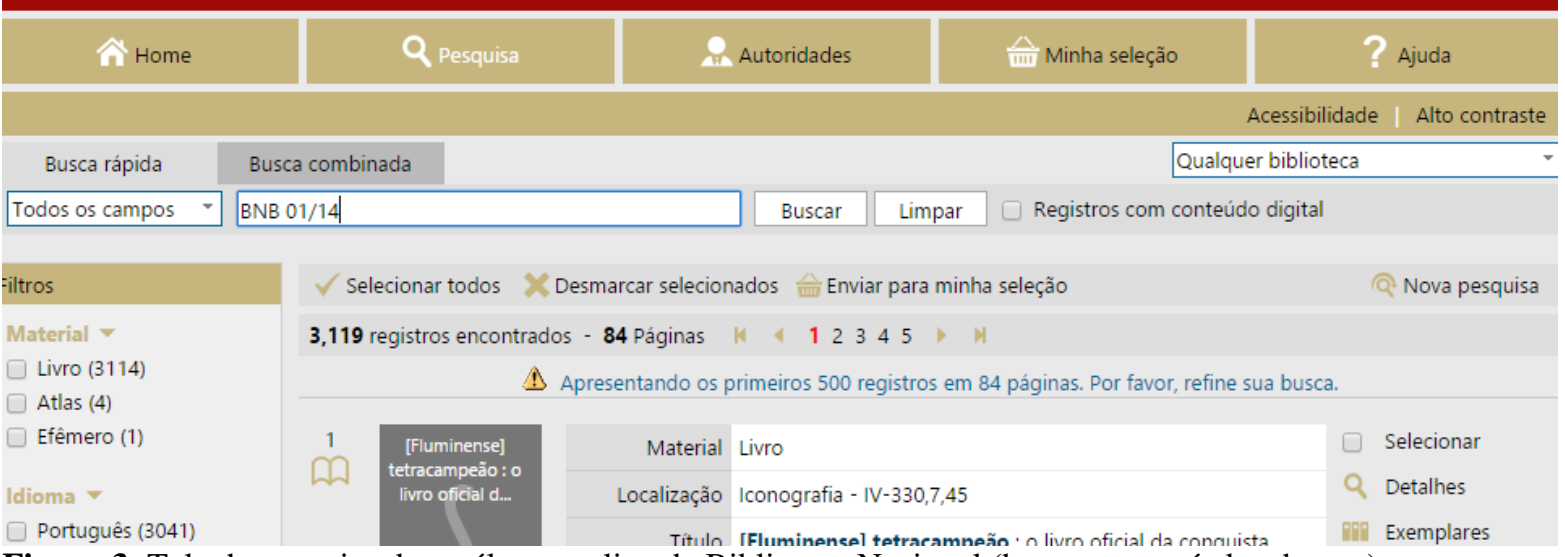

Figura 3: Tela de pesquisa do catálogo on-line da Biblioteca Nacional (busca por períodos do ano). 
Fonte: Catálogo on-line da Biblioteca Nacional.

Isto posto, podemos depreender que a Bibliografia Nacional brasileira não está sendo editada e muito menos está acessível segundo consta no site da BN. Podemos, ainda, depreender que há uma grave confusão entre catálogo e bibliografia, mas nos reservaremos a tecer maiores comentários na seção subsequente.

\section{Reflexões e inflexões sobre a 'Memória Vegetal'}

Há outros inimigos dos livros: aqueles que os escondem. Há muitos modos de esconder os livros. Não criando uma rede suficiente de bibliotecas volantes, escondem-se os livros, que afinal custam dinheiro, das pessoas que não o podem comprar. Dificultando o acesso às bibliotecas, de tal modo que para pedir dois livros seja necessário preencher dez fichas e esperar uma hora, subtraem-se os livros aos seus consumidores normais. Também se escondem os livros abandonando nossas grandes bibliotecas históricas à deterioração. É preciso combater aqueles que escondem os livros, porque são tão perigosos quanto as brocas. Não usaremos o Zyklon $^{15}$, mas as armas políticas e civis mais adequadas. Mas devemos saber que eles são inimigos de nossa memória coletiva (ECO, 2010, p. 26).

Apropriando-nos da ideia de Umberto Eco (2010), adicionamos que aqueles que escondem os livros, também o fazem na organização (ou seria desorganização?) de catálogos e outras fontes de informação, na omissão perante suas responsabilidades legais, nas sombras que a legislação ou o desconhecimento do público permitem.

Incisivamente, a BN não cumpre o seu papel, seja porque ela também sofre com o abandono das "grandes bibliotecas históricas à deterioração" e a consequente vontade de esconder o livro, seja pela sua falta de ação no seu dever.

Claro que a questão bibliográfica nacional perpassa aspectos legais que não serão alvo deste breve estudo, mas vê-se, mesmo em sua atuação como instituição responsável pela salvaguarda da memória nacional, hiatos difíceis de serem preenchidos. Grings; Pacheco (2010) e Morais (2016), chamam atenção para a literatura de cordel, ausente nas prateleiras da instituição, mas de suma importância para a formação identitária do brasileiro, sobretudo o nordestino. Outros exemplos ainda podem ser dados, como a dos pequenos editores ou autores independentes, que, diante dos custos de registro e envio das obras, acabam por optar por não realiza-los.

\footnotetext{
${ }^{15}$ Referência ao veneno utilizado para acabar com infestações de brocas.
} 
A questão aqui é mais ampla, discorre sobre políticas nacionais de incentivo ao Depósito Legal e ao registro autoral das obras, mas, sobretudo, à vontades políticas de um ideal de construção de uma Biblioteca Nacional, afinal, enquanto símbolo e responsável pela salvaguarda da memória nacional, suas prateleiras revelam muito mais tensões do que um primeiro olhar permite.

A formação da memória nacional é um fardo pesado, repleto de escolhas e omissões, a Biblioteca, como dizia Peregrino da Silva no início do século XX (SILVA, 1911), é o maior repositório passivo da América Latina - fato ainda em vigência hoje, mas a passividade à qual ele se referia diz respeito à ser o centro para onde deveriam confluir todas as obras nacionais, a ser beneficiada pela Lei de Depósito Legal, mas não no sentido de não fazer lobby em prol da causa nacional, afinal, foi por suas mãos que a Lei de 1907 foi aprovada, claro, sujeitando os senadores à pressão necessária (SILVA, 1908).

Ademais, a ausência de uma Bibliografia Nacional tem impacto direto na memória intelectual brasileira, não sabemos, afinal, quais áreas do conhecimento produzem mais ou menos no país, o que poderia, sob um ângulo otimista, servir de subsídio para o direcionamento de políticas públicas educacionais para alguns campos do saber etc. Além de que não sabemos em números reais quem tem cumprido ou não a Lei de Depósito Legal.

É nítido que a Lei deveria trazer punições à quem a descumprisse, mas ainda é notório o desconhecimento por parte do grande público de tal arcabouço legal. De fato, a BN coopera com a invisibilidade do livro ao não exercer suas missões, ao não "difundir os registros da memória bibliográfica e documental nacional"; ao atuar, em parte, como "centro referencial de informações bibliográficas"; ao não atuar "como órgão responsável pelo controle bibliográfico nacional"; ao não "assegurar o cumprimento da legislação relativa ao depósito legal"; e ao não compreender a diferença entre um catálogo e uma bibliografia.

Em termos memorialísticos, aquilo que Araújo (2015) menciona ter acontecido em Buda, pode perfeitamente acontecer ao Brasil, afinal, quantas obras surgem e desaparecem em nosso país sem que as apareçam na Bibliografia Nacional, sem que tenham a chance de deixarem o seu rastro. É notório, e reiteramos, o descaso com a Nacional, mas, por sua vez, ela mesma é ativa no descaso com que trata o 'Nacional', os registros de memória da produção intelectual brasileira (ECO, 2010; NORA, 1991; HALBWACHS, 2004). Afinal, qual a solução 
para o efetivo cumprimento da Lei de Depósito Legal? Ademais, como inserir a completude ${ }^{16}$ de tal produção nas estantes da Biblioteca?

Por fim, como nos esclarece Otlet (1934), o catálogo remete à própria biblioteca, ou seja, tem início, meio e fim no mesmo local, já a bibliografia, joga o livro no mundo, instigando a curiosidade, a cooperação e preservando do esquecimento total os "frutos do espírito humano". A BN segue uma lógica correta, mas extremamente arrogante, ao achar que seu catálogo pode ser entendido como Bibliografia Nacional, mas, é necessário despir-se da soberba e entender que o 'Nacional' que ela representa hoje está bem aquém do Nacional que o Brasil é, mesmo em termos bibliográficos.

\footnotetext{
${ }^{16}$ Sabemos que quando se trata de memória, a completude é impossível, mas a utilizamos aqui no sentido de alcançar (recolher) o maior número de obras possíveis.
} 


\section{Referências}

ARAÚJO, A. V. F. Pioneirismo bibliográfico em um polímeta do séc. XVI: Conrad Gesner. Informação \& Informação, v. 20, n. 2, p. 118-142, maio/ago. 2015.

BALSAMO, L. La bibliografia: historia de uma tradición. Gijón: Trea, [200-].

BRASIL. Decreto ${ }^{\circ}$ 433, de 3 de julho de 1847. Coleção de Leis do Império do Brasil, p. 22, 1847. Disponível em: <http://www2.camara.leg.br/legin/fed/decret/1824-1899/decreto433-3-julho-1847-560144-publicacaooriginal-82761-pl.html> . Acesso em: 28 mar. 2016.

Decreto ${ }^{\circ} 1.825$, de 20 de dezembro de 1907: Dispõe sobre a remessa de obras impressas á Bibliotheca Nacional. Diário Oficial da União, Brasília, 21 dez. 1907. Disponível em: <http://www2.camara.leg.br/legin/fed/decret/1900-1909/decreto-1825-20dezembro-1907-509239-publicacaooriginal-1-pe.html>. Acesso em: 23 maio 2012.

. Lei n. 10.994, de 14 de dezembro de 2004. Diário Oficial da União, 15 dez. 2004. Disponível em: <http://www.planalto.gov.br/ccivil_03/_ato2004-2006/2004/lei/110994.htm>. Acesso em: 28 mar. 2016.

BIBLIOGRAPHIA Brazileira. Revista Sul Amricana, ano 1, n. 2, fev. 1888.

BIBLIOTECA NACIONAL (Brasil). Apresentação. Rio de Janeiro: Biblioteca Nacional, [200-a]. Disponível em: 〈http://www.bn.br/sobre-bn/apresentacao >. Acesso em: 20 mar. 2016.

Competências e atividades. Rio de Janeiro: Biblioteca Nacional, [200-b]. Disponível em: 〈http://www.bn.br/sobre-bn/competencias-atividades〉. Acesso em: 20 mar. 2016.

BULLETIN DE L'INSTITUT INTERNATIONAL DE BIBLIOGRAPHIE, ano 3, 1908.

CALDEIRA, P. T.; CARVALHO, M. L. B. O problema editorial da Bibliografia Brasileira Corrente. Revista Brasileira de Biblioteconomia e Documentação, v. 13, n. 3/4, p. 210-216, jul./dez. 1980.

CALLEGARI, J. Saiba mais sobre o Index Librorum Prohibitorum, a lista de livros proibidos na história. História, 04 jul. 2012. Disponível em:

<http://guiadoestudante.abril.com.br/aventuras-historia/saiba-mais-index-librorumprohibitorum-lista-livros-proibidos-historia-691501.shtml>. Acesso em: 28 mar. 2016.

CHARTIER, R. O príncipe, a biblioteca e a dedicatória. In: BARATIN, M.; JACOB, C. (Orgs.). O poder das bibliotecas: a memória dos livros no ocidente. Rio de Janeiro: UFRJ, 2000. p. 182-199.

CUNHA, M. B.; CAVALCANTI, C. R. O. Dicionário de biblioteconomia e arquivologia. Brasília, DF: Briquet de Lemos, 2008.

ECO, U. A memória vegetal e outros escritos sobre bibliofilia. Rio de Janeiro: Record, 2010 . 
ENCICLOPAEDIA BRITANNICA. Jesuits. [S. 1.]: Enciclopaedia Britannica, c2015c. Disponível em: <http://www.britannica.com/topic/Jesuits>. Acesso em: 21 out. 2015.

JESUITS. In: ENCICLOPAEDIA BRITANNICA, c2015. Disponível em: <http://www.britannica.com/topic/Jesuits >. Acesso em: 21 out. 2015.

FONSECA, E. N. Bibliografia brasileira corrente: evolução e estado atual do problema. Ciência da Informação, v. 1, n. 1, p. 9-14, 1972.

GRINGS, L.; PACHECO, S. A Biblioteca Nacional e o Controle Bibliográfico Nacional: situação atual e perspectivas. InCID: revista de ciência da informação, Ribeirão Preto, v. 1, n. 2, p. 77-88, jul./dez. 2010.

HALBWACHS, M. A memória coletiva. São Paulo: Centauro, 2004.

MAGALHÃES, B. Prefácio. Boletim bibliographico da Bibliotheca Nacional do Rio de Janeiro, ano 1, n. 1, jan./mar. 1918.

A Bibliotheca em 1918. Annaes da Bibliotheca Nacional do Rio de Janeiro, v. 41 42, p. 270-303, 1919-1920. Disponível em:

<http://objdigital.bn.br/acervo_digital/anais/anais_041-042_1919_20.pdf > $>$. Acesso em: 10 fev. 2013.

MONTE-MÓR, J. M. Controle bibliográfico nacional. Revista da Escola de Biblioteconomia da UFMG, Belo Horizonte, v. 10, n. 1, p. 1-12, mar. 1981.

MORAIS, A. G. A literatura de cordel no depósito legal: aspectos da captação de acervo. 2016. Paper.

NORA, P. Entre memória e história: a problemática dos lugares. Proj. História, São Paulo, n. 10, p. 7-28, dez, 1993.

OTLET, P. Traité de Documentation: le livre sur le livre, théorie et pratique. Bruxelas: Mundaneum, 1934. Disponível em:

<http://lib.ugent.be/fulltxt/handle/1854/5612/Traite_de_documentation_ocr.pdf $>$. Acesso em 13 set. 2012.

REYES GÓMEZ, F. Manual de bibliografia. Madrid: Castalia Instrumenta, 2010.

SCHWARTZMAN, S. Um espaço para a ciência: a formação da comunidade científica no Brasil. Brasília: Ministério da Ciência e da Tecnologia, 2001.

SILVA, M. C. P. A Bibliotheca Nacional em 1907. Annaes da Bibliotheca Nacional do Rio de Janeiro, v. 30, p. 319-343, 1908. Disponível em:

<http://objdigital.bn.br/acervo_digital/anais/anais_030_1908.pdf >. Acesso em: 10 fev. 2013.

A Bibliotheca Nacional em 1911. Annaes da Bibliotheca Nacional do Rio de Janeiro, v. 34, p. 648-684, 1912. Disponível em:

<http://objdigital.bn.br/acervo_digital/anais/anais_034_1912.pdf >. Acesso em: 10 fev. 2013. 